\title{
The Effect of Different Pillow Heights on the Parameters of Cervicothoracic Spine Segments
}

\author{
Hyung Cheol Kim, Hyo Sub Jun, Ji Hee Kim, Jun Hyong Ahn, In Bok Chang, \\ Joon Ho Song, Jae Keun Oh \\ Department of Neurosurgery, Sacred Heart Hospital, Hallym University College of Medicine, Anyang, Korea
}

Objective: To investigate the effect of different pillow heights on the slope of the cervicothoracic spine segments. Methods: A prospective analysis of data from 16 asymptomatic adults (aged 20 to 30 years) was carried out. Exclusion criteria were history of injury or accident to the cervicothoracic spine, cervicothoracic spine surgery, or treatment for neck symptoms. We used three different pillow heights: flat $(0 \mathrm{~cm}), 10-\mathrm{cm}$, and $20-\mathrm{cm}$ pillows. Cervical sagittal parameters, measured with radiography, included; C2-7 Cobb's angle, T1 slope (T1S), thoracic inlet angle (TIA), and neck tilt (NT). Statis- tical analyses were performed using Spearman correlation coefficients.

Results: As the height of the pillow increased, the T1S \& C2-7 Cobb's angle increased while the NT values tended to decrease. The TIA values, however, remained constant. Additionally, there was a statistically significant sex difference in T1S with the 0 -cm pillow $(\mathrm{p}=0.01)$, and in NT with the 20-cm pillow $(\mathrm{p}=0.01)$.

Conclusion: From the data obtained in this study, we recommend that the most suitable pillow height is $10 \mathrm{~cm}$, considering the normal cervical lordosis.

Key Words: Pillow • Lordosis • Cervical spine

\section{INTRODUCTION}

Many patients present with symptoms related to the cervicothoracic spine, such as neck pain, scapular pain, and headaches ${ }^{7}$. Changing pillows can significantly relieve cervical pain, scapular pain, and headaches ${ }^{2,5-7,9)}$, although many people appear to have made poor pillow choices, as low pillow comfort and cervicothoracic symptoms upon waking are commonly reported ${ }^{4}$. While patients continue to seek advice on pillow choice, there has been limited research to assess the effects of varying pillow heights on cervical spine posture. As such, appropriate recommendations cannot as yet be made.

This study reports the effects of three different pillow heights on the slope of the cervicothoracic spine segments when resting in the supine position.

- Received: June 4, 2015 - Revised: August 13, 2015

- Accepted: August 20, 2015

Corresponding Author: Jae Keun Oh, MD

Department of Neurosurgery, Hallym University Sacred Heart Hospital,

22, Gwanpyeong-ro 170beon-gil, Dongan-gu, Anyang-si, Gyeonggi-do

14068, Korea

Tel: +82-31-380-3771, Fax: +82-31-380-4118

E-mail: ohjaekeun@gmail.com

$\otimes$ This is an Open Access article distributed under the terms of the Creative

Commons Attribution Non-Commercial License (http://creativecommons.org/

licenses/by-nc/3.0/) which permits unrestricted non-commercial use, distribution,

and reproduction in any medium, provided the original work is properly cited.

\section{MATERIALS AND METHODS}

\section{Study Participants}

A cohort of 16 asymptomatic adult volunteers, aged between 20 and 30 years, were enrolled in this study. All participants provided written informed consent prior to inclusion. We included individuals who had no history of any spinal diagnosis, symptoms, or treatment, and excluded cases where there was an accident or injury to the cervicothoracic spine in the preceding year. Patients currently receiving treatment for neck symptoms were also excluded.

\section{Preparation and Test Position}

Participants were permitted to sit up briefly to stretch and move their necks between each pillow trial. Participants assumed a standard supine position with their head resting on the pillow with the external occipital protuberance at the center of the pillow. Participants lay with their eyes facing the ceiling.

\section{Analysis of Simple Radiographs}

We measured four morphological parameters. These para- 
meters consisted of the thoracic inlet angle (TIA), T1 slope (T1S), neck tilt (NT), and C2-7 Cobb's angle. As depicted in Fig. 1, the TIA was considered the angle formed by a line from the center of the T1 upper endplate (T1UEP) vertical to the T1UEP, and a line connecting the center of the T1UEP and the upper end of the sternum. The T1S was defined as the angle formed between the horizontal plane and the T1UEP. The NT was defined as the angle formed by a line drawn in the upper end of the sternum and a line connecting the center of the T1UEP and the upper end of the sternum. The C2-C7 angle was measured by the formal Cobb methods as the angle between the horizontal line of the $\mathrm{C} 2$ lower endplate and the horizontal line of the C7 lower endplate (Fig. 1).

\section{Statistical Analysis}

The PACS system ( $p$ view, INFINITT, Seoul, Korea) was determined by one observer for the measurement. Each parameter was independently measured twice. The mean and standard deviations of all measurements were calculated.

Correlations between parameters of interest in this study were analyzed with the Mann-Whitney test and Spearman

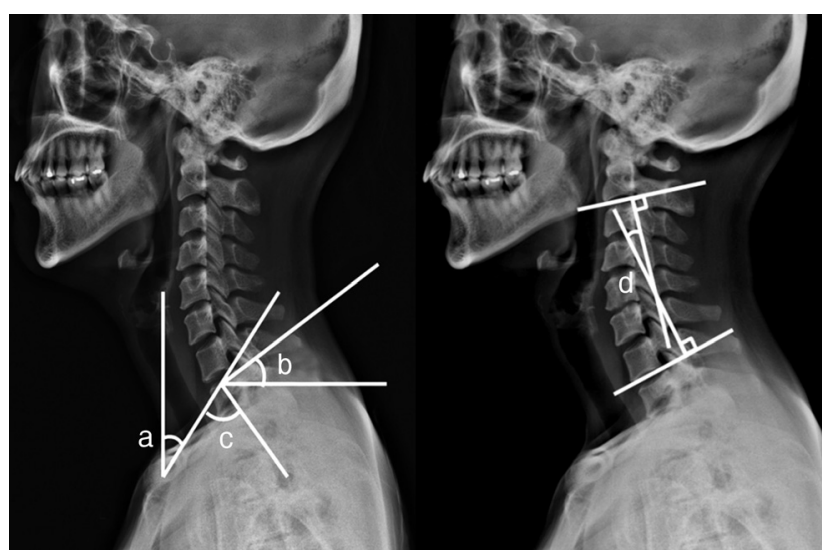

Fig. 1. Schematic drawing of the measured angles of the cervicothoracic spine segments. a: Neck tilt; b: T1 slope; c: Thoracic inlet angle; d: C2-7 Cobb's angle. coefficients. All statistical analyses were performed using SPSS (version 18.0, SPSS, Chicago, IL, USA). Data are presented as mean \pm standard deviation. A $\mathrm{p}<0.05$ was considered statistically significant.

\section{RESULTS}

The mean ages of the study participants were $29.38 \pm 2.23$ and 29.25 \pm 3.11 years for men and women, respectively. Table 1 shows the mean values for each of the measured parameters stratified by sex. With a greater pillow height, the T1S and C2-7 Cobb's angle seen on radiographs were greater. For pillow heights of 0,10 , and $20 \mathrm{~cm}$, the T1S were $12.92 \pm 5.71^{\circ}, 17.33$ $\pm 7.42^{\circ}$ and $28.79 \pm 5.71^{\circ}$, respectively; and the C2-7 Cobb's angles were $10.34 \pm 7.37^{\circ}, 14.93 \pm 6.77^{\circ}$, and $17.40 \pm 7.33^{\circ}$, respectively. Additionally, with increasing pillow height, the

Table 1. Parameters of cervicothoracic spine segments ${ }^{*}$

\begin{tabular}{lrccc}
\hline \hline & & Total & Male & Female \\
\hline T1Slope & Sitting & $22.82 \pm 5.54$ & $19.21 \pm 4.65$ & $26.43 \pm 3.79$ \\
$\left(^{\circ}\right)$ & $0 \mathrm{~cm}$ & $12.92 \pm 5.71$ & $8.76 \pm 2.11$ & $17.07 \pm 5.09$ \\
& $10 \mathrm{~cm}$ & $17.33 \pm 7.42$ & $11.72 \pm 5.15$ & $22.94 \pm 4.42$ \\
& $20 \mathrm{~cm}$ & $28.79 \pm 5.71$ & $27.74 \pm 6.28$ & $29.82 \pm 5.29$ \\
NeckTilt & Sitting & $43.98 \pm 5.60$ & $41.82 \pm 5.99$ & $46.14 \pm 4.54$ \\
$\left(^{\circ}\right)$ & $0 \mathrm{~cm}$ & $51.27 \pm 8.13$ & $51.26 \pm 10.84$ & $51.27 \pm 4.90$ \\
& $10 \mathrm{~cm}$ & $45.80 \pm 9.52$ & $39.70 \pm 4.53$ & $51.89 \pm 9.43$ \\
& $20 \mathrm{~cm}$ & $43.11 \pm 13.03$ & $33.69 \pm 7.02$ & $52.54 \pm 10.58$ \\
Cobb's & Sitting & $9.15 \pm 4.95$ & $8.96 \pm 4.68$ & $9.33 \pm 5.53$ \\
Angle & $0 \mathrm{~cm}$ & $10.34 \pm 7.37$ & $9.16 \pm 4.86$ & $11.52 \pm 9.47$ \\
$\left(^{\circ}\right)$ & $10 \mathrm{~cm}$ & $14.93 \pm 6.77$ & $16.46 \pm 6.97$ & $13.40 \pm 6.65$ \\
& $20 \mathrm{~cm}$ & $17.40 \pm 7.33$ & $19.46 \pm 6.24$ & $15.34 \pm 8.16$ \\
& Sitting & $66.80 \pm 7.14$ & $61.03 \pm 2.83$ & $72.57 \pm 5.02$ \\
TIA $\left(^{\circ}\right)$ & $0 \mathrm{~cm}$ & $64.18 \pm 9.49$ & $60.02 \pm 11.22$ & $68.34 \pm 5.23$ \\
& $10 \mathrm{~cm}$ & $63.12 \pm 14.55$ & $51.42 \pm 6.21$ & $74.83 \pm 10.10$ \\
& $20 \mathrm{~cm}$ & $71.89 \pm 13.02$ & $61.43 \pm 6.08$ & $82.35 \pm 8.07$ \\
\hline
\end{tabular}

Data are presented as mean \pm standard deviation

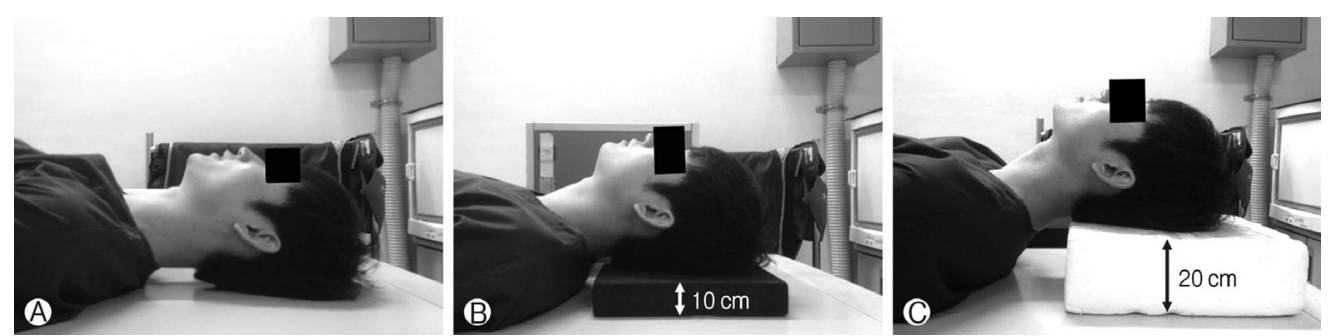

Fig. 2. Photographs of participants in supine position using pillows of varying height. (A) $0 \mathrm{~cm}$; (B) 10-cm pillow; (C) 20-cm pillow. 
NT value tended to decrease, and the TIA values remained constant with the $0 \mathrm{~cm}$ and $10 \mathrm{~cm}$ pillow. However, the TIA values with $20-\mathrm{cm}$ pillow were different from the other pillow heights.

The TIA with the $10 \mathrm{~cm}$ pillow had a significant correlation $(\mathrm{p}<0.05)$ with the T1S with the $10 \mathrm{~cm}$ pillow $(r=0.829)$ and the NT with the $10 \mathrm{~cm}$ pillow ( $\mathrm{r}=0.812)$. In addition, the TIA with the $20 \mathrm{~cm}$ pillow had a significant correlation $(\mathrm{p}<0.05)$ with the NT with the $20 \mathrm{~cm}$ pillow $(\mathrm{r}=0.821)$.

There were, however, no statistically significant differences in the measured parameters between male and female study participants, with the exception of differences in T1S with the $0 \mathrm{~cm}$ pillow $(\mathrm{p}=0.01)$ and the NT with the $20 \mathrm{~cm}$ pillow $(\mathrm{p}=$ $0.01)$.

\section{DISCUSSION}

As is already known, optimal sagittal alignment of the spine occurs when all components are in proper balance ${ }^{14)}$. The global balance and regional balance alignment is maintained in each curvature ${ }^{8}$. If this balance is altered, clinical symptoms related to unbalanced alignment arise.

The T1S and other cervical parameters have been identified as radiographic parameters that are greatly correlated with cervical sagittal balance ${ }^{10)}$. Indeed, the T1 sagittal angle is a measurement that may be very useful in evaluating sagittal balance. In particular, it has great utility where long films cannot be obtained $^{11)}$. Lee et al. ${ }^{12)}$ reported that the TIA and T1S could be used to predict the physiological alignment of the cervical spine on radiographs. Patrick et al. ${ }^{11)}$ demonstrated that patients whose T1S value falls outside the range of $13^{\circ}$ to $25^{\circ}$ should be sent for full-column radiographs for complete evaluation of their sagittal balance. On the other hand, although patients with a T1S value between $13^{\circ}$ and $25^{\circ}$ mostly had better sagittal balance than patients with values outside this range, its occurrence does not guarantee normal sagittal balance. Unfortunately, there are no studies to date that have established normative sagittal T1S values. However, in the aforementioned study by Patrick et al. ${ }^{14)}$, their analysis has shown that when the T1S was higher than $25^{\circ}$, all patients had at least $10 \mathrm{~cm}$ of positive sagittal imbalance. Their study also showed that patients with a negative sagittal balance had mostly low T1S values, usually below $13^{\circ}$ of angulation ${ }^{11)}$. In our study, we found that the T1S value with the $10 \mathrm{~cm}$ pillow height was between $13^{\circ}$ and $25^{\circ}$ for normal sagittal balance. We could advise that the $10 \mathrm{~cm}$ pillow height is most suitable for optimal cervical alignment. However, the pillow height of $10 \mathrm{~cm}$ is just a numerical value taking into consideration only the cervical parameter and not considering the comfort and satisfaction of patients. The- refore, this value is not an absolute figure.

Although T1S is influenced by aging or posture, it is not a constant parameter. On the other hand, TIA does not change with position or increase of thoracic kyphosis under any condition, similar to the pelvic inlet of the pelvis. The TIA is a constant parameter because, anatomically, the cervical spine is placed on top of the TI, a fixed circular bony structure without range of motion that is composed of the T1 vertebral body, the first ribs on both sides, and the upper part of the sternum $^{17}$. The sagittal balance of the cervical spine adjusts and can be influenced by the shape and orientation of T1. They concluded that the $\mathrm{C} 2-\mathrm{C} 7$ angle increases with increasing T1S by radiography. Park et al. ${ }^{14)}$ assessed the sagittal parameters of the cervical spine using CT scans in the supine position and concluded that the $\mathrm{C} 2-\mathrm{C} 7$ angle increased as the T1S increased. They also reconfirmed that the TIA can be considered as a fixed reference value ${ }^{14)}$. However, in our study, we measured different TIA values with the $20 \mathrm{~cm}$ pillow than other pillow height. Although there are many reasons for this, we thought an error possibly occurred when measuring the angle and the higher pillow height changed the TIA. Additional investigations and considerations of the differences in T1A are necessary.

Loss of cervical lordosis is a complicating factor in the treatment of the cervical spine, and understanding the effects and prognosis of a loss of cervical lordosis is crucial to treatment. However, an embryological basis can be helpful for understanding the pathogenesis of cervical lordosis. In 1977, Bagnall et al. ${ }^{1)}$ demonstrated that cervical lordosis is formed at 9.5 weeks of gestation. In 195 fetuses, they found that at 9.5 weeks, $83 \%$ of fetuses have cervical lordosis, $11 \%$ have a military configuration, and only $6 \%$ of fetuses are in the kyphotic position of the cervical spine ${ }^{1)}$. In other words, by 9.5 weeks $94 \%$ of fetuses begin to use their posterior cervical muscles to begin forming the cervical curve. The lordosis begins to form before birth, and once the child begins to lift his/her head, the lordosis becomes clearer. Cervical lordosis has been theorized to exist for biomechanical reasons related to weight distribution, structural support, energy efficiency, and shock absorption. In daily activity, cervical lordosis better distributes forces than a cervical spine which has lost its normal lordosis ${ }^{3)}$. Some studies also reported that an asymptomatic cervical spine did not always show normal lordotic alignment, as kyphotic alignment was revealed in $2 \%$ to $35 \%$ of individuals ${ }^{8,13,16}$.

Although the Cobb method works well for the rectangular vertebrae of the thoracic and lumbar spine, it may be less precise for measuring the cervical spine, which has trapezoidal vertebrae $^{13)}$. The Gore method, which uses the posterior vertebral body line as opposed to the superior and inferior end plate lines used by the Cobb method, is considered to be more 
reproducible when measuring the cervical sagittal alignment ${ }^{15)}$. In the present study, however, we did not use the Gore method, because the Cobb method was more familiar and generally known.

A limitation of the present study is the uneven distribution of data in the cohort. To estimate the result for a normative cohort we included only 16 individuals. Since our cohort might not contain all the representative patterns of sagittal alignment, we analyzed the non-parametric statistical test. An additional study, with a larger number of cases, is still needed to be able to carry out an age, body weight, height, and sex-matched controlled investigation and confirm the result of the current study. In other words, our study is a preliminary study, so further studies with more participants are needed in the future. Nevertheless, the study participants included were healthy, young, and without a history of spinal problems. In addition, our study did not evaluate the comfort, pain relief, and level of satisfaction of each pillow, Therefore, further study is required. An active discussion about the T1S and cervical sagittal alignment is also in progress. Some studies propose an approximate average value for cervical sagittal alignment, but there is no "gold standard" established as yet, and additional investigations of cervical alignment are still necessary.

\section{CONCLUSION}

From the data obtained in this study, we recommend that the most suitable pillow height is $10 \mathrm{~cm}$ considering the normal cervical lordosis. Additionally, the NT value decreased with increasing pillow height, whereas TIA values tended to remain constant.

\section{REFERENCES}

1. Bagnall KM, Harris PF, Jones PR: A radiographic study of the human fetal spine. 1 . The development of the secondary cervical curvature. J Anat 123:777-782, 1977

2. Bernateck M, Karst M, Merkesdal S, Fischer MJ, Gutenbrunner C: Sustained effects of comprehensive inpatient rehabilitative treatment and sleeping neck support in patients with chronic cervicobrachialgia: a prospective and randomized clinical trial. Int J Rehabil Res 31:342-346, 2008

3. Gay RE: The curve of the cervical spine: variations and signi- ficance. J Manipulative Physiol Ther 16:591-594, 1993

4. Gordon SJ, Grimmer-Somers K: Your pillow may not guarantee a good night's sleep or symptom-free waking. Physiother Can 63:183-190, 2011

5. Gordon SJ, Grimmer-Somers K, Trott P: Pillow use: the behaviour of cervical pain, sleep quality and pillow comfort in side sleepers. Man Ther 14:671-678, 2009

6. Gordon SJ, Grimmer-Somers KA, Trott PH: Pillow use: the behavior of cervical stiffness, headache and scapular/arm pain. J Pain Res 3:137-145, 2010

7. Gordon SJ, Grimmer-Somers KA, Trott PH: A randomized, comparative trial: does pillow type alter cervico-thoracic spinal posture when side lying? J Multidiscip Healthc 4:321-327, 2011

8. Gore DR, Sepic SB, Gardner GM: Roentgenographic findings of the cervical spine in asymptomatic people. Spine (Phila Pa 1976) 11:521-524, 1986

9. Hagino C, Boscariol J, Dover L, Letendre R, Wicks M: Before/ after study to determine the effectiveness of the align-right cylindrical cervical pillow in reducing chronic neck pain severity. $\mathrm{J}$ Manipulative Physiol Ther 21:89-93, 1998

10. Jun HS, Chang IB, Song JH, Kim TH, Park MS, Kim SW, et al: Is it possible to evaluate the parameters of cervical sagittal alignment on cervical computed tomographic scans? Spine (Phila Pa 1976) 39:E630-636, 2014

11. Knott PT, Mardjetko SM, Techy F: The use of the T1 sagittal angle in predicting overall sagittal balance of the spine. Spine J 10:994-998, 2010

12. Lee SH, Kim KT, Seo EM, Suk KS, Kwack YH, Son ES: The influence of thoracic inlet alignment on the craniocervical sagittal balance in asymptomatic adults. J Spinal Disord Tech 25: E41-47, 2012

13. Matsumoto M, Fujimura Y, Suzuki N, Toyama Y, Shiga H: Cervical curvature in acute whiplash injuries: prospective comparative study with asymptomatic subjects. Injury 29:775-778, 1998

14. Park JH, Cho CB, Song JH, Kim SW, Ha Y, Oh JK: T1 Slope and Cervical Sagittal Alignment on Cervical CT Radiographs of Asymptomatic Persons. J Korean Neurosurg Soc 53:356-359, 2013

15. Silber JS, Lipetz JS, Hayes VM, Lonner BS: Measurement variability in the assessment of sagittal alignment of the cervical spine: a comparison of the gore and cobb methods. J Spinal Disord Tech 17:301-305, 2004

16. Takeshima T, Omokawa S, Takaoka T, Araki M, Ueda Y, Takakura Y: Sagittal alignment of cervical flexion and extension: lateral radiographic analysis. Spine (Phila Pa 1976) 27:E348355,2002

17. Urschel HC Jr.: Anatomy of the thoracic outlet. Thorac Surg Clin 17:511-520, 2007 